\title{
FORMAÇÃO DOCENTE E CONTAÇÃO DE HISTÓRIAS: A LEITURA LITERÁRIA NA ESCOLA
}

\author{
TEACHING TRAINING AND STORY TELLING: \\ LITERARY READING IN SCHOOL
}

\author{
Cristina Rothier Duarte* \\ Ana Paula Serafim Marques da Silva** \\ Girlene Marques Formiga ${ }^{* * *}$
}

Resumo: Neste artigo, objetivamos relatar uma prática de leitura literária realizada durante a formação de professores de uma escola da rede pública municipal de ensino de João Pessoa-PB, em que trabalhamos com a contação de As aventuras de Bambolina (2006), de Michelle Iacocca. Os objetivos específicos são: relatar o desenvolvimento da prática de leitura do nosso corpus proposta por Dalvi e Silva (2016), bem como tecer considerações a respeito da importância das estratégias de leitura, especificamente, sobre o uso das conexões, recurso eleito para o trabalho com os professores e com os alunos, tratadas por Solé (1998) e por Girotto e Souza (2010). Metodologicamente, empregamos a pesquisa descritivointerpretativa de cunho qualitativo para a realização da revisão bibliográfica. Como resultados, verificamos que a leitura literária, quando planejada e embasada teoricamente, constitui uma importante ferramenta para a formação leitora dos envolvidos.

Palavras-chave: Contação de histórias; formação de professores; estratégias de leitura.

Abstract: This article presents as general objective to report a literary practice practiced during the training of teachers of a public school in João Pessoa-PB, in which we work with the account of the narrative of images, The adventures of Bambolina (2006), by Italian writer and illustrator Michelle Iacocca. The specific objectives are: to report the development of the reading practice of our corpus proposed by the authors Maria Amélia Dalvi and Kenya Adriana Silva (2016), as well as to make considerations about the importance of reading strategies, specifically, on the use of connections, This is a resource chosen for working with teachers and students, based on the suggestions of Isabel Solé (1998) and Cyntia Graziella Girotto and Renata Junqueira de Souza (2010). Methodologically, we used descriptive-interpretive research of a qualitative nature for the accomplishment of the bibliographical revision and for the comprehension of the text as a tool for literary literacy in the school. As results, we verified that literary reading, when planned and theoretically based, constitutes an important tool for the reading formation of children and teachers.

Keywords: Storytelling; teacher training; reading strategies.

\section{Introdução}

Diante das mudanças ocasionadas pelas transformações socioculturais, bem como pedagógicas e políticas, há a exigência de que profissionais da educação constantemente tenham acesso a processos formativos que lhe permitam a atualização e o afeiçoamento de conhecimentos teórico-metodológicos afeitos à prática escolar, por meio da formação continuada. Nesse sentido, este trabalho trata-se de um relato de experiência vivenciado durante a formação continuada realizada em uma escola da rede municipal de João Pessoa-PB, sob a coordenação da Professora Daniela Maria

\footnotetext{
* Mestranda em Letras pelo Programa de Pós-graduação em Letras na Universidade Federal da Paraíba. cristinarothierduarte@gmail.com

** Mestre em Letras Programa de Pós-graduação em Letras na Universidade Federal da Paraíba. anapaulasms@gmail.com

*** Doutora em Literatura Programa de Pós-graduação em Letras na Universidade Federal da Paraíba. Professora do Instituto Federal de Educação, Ciência e Tecnologia da Paraíba desde 1995. É docente na Licenciatura em Letras com habilitação em Língua Portuguesa, orientando pesquisas principalmente na área de Literatura e Ensino. gformiga@uol.com.br
} 
Segabinazi (PPGL/UFPB), em que apresentamos metodologias e procedimentos empregados na formação direcionada para o estudo de estratégias de leitura - mais especificamente, a conexão -, de modo a conjugar conhecimento teórico e prático.

Como objetivo deste trabalho, assim buscamos: i. apresentar a nossa prática na formação de professores com intermédio da contação da narrativa de imagens $A s$ aventuras de Bambolina (2006), do escritor e ilustrador italiano radicado no Brasil Michelle Iacocca; ii. tecer ponderações sobre a formação de professores de literatura, a partir do diálogo com as reflexões de Maurice Tardif (2002); iii. relatar o desenvolvimento da prática de leitura realizada junto aos professores durante a formação; e iv. trazer considerações a respeito da importância das estratégias de leitura para promoção do letramento literário. Para tanto, utilizamos como aporte teórico as considerações de Solé (1998), de Girotto e Souza (2010), de Tardif (2002), entre outros. Metodologicamente, empregamos a pesquisa descritivo-interpretativa de cunho qualitativo para a realização da revisão bibliográfica e para a compreensão do texto como ferramenta para o letramento literário na escola.

Os resultados apontam para a importância que a formação continuada assume em um cenário em que a leitura da literatura ainda não tem um lugar assegurado dentro do espaço escolar, haja vista a adoção de práticas de leituras improvisadas sem a possibilidade de uma construção respaldada pelo conhecimento teórico-metodológico. Os resultados direcionam ainda no sentido de que a leitura literária, quando planejada e embasada teoricamente, constitui uma importante ferramenta para a formação leitora das crianças e dos professores, conferindo a estes últimos motivação e segurança para, cada vez mais, levarem o texto literário para a sala de aula.

\section{A formação de professores à luz da teoria}

Uma formação docente considerada apropriada para o ensino da literatura, no sentido de ser dotada de uma abordagem eficaz do texto literário em sala de aula, compreende um processo de construção de conhecimento em que o professor se sinta apto para dar resposta a três questionamentos básicos, porém mobilizadores de diversos saberes: (a) qual obra posso levar para minha turma? - a resposta a essa pergunta implica no conhecimento acerca da experiência de leitura de seus alunos, de suas preferências e da adequação da obra para a faixa etária de modo que seja significativa no processo de construção de seu aprendizado; (b) eu conheço bem essa obra? - para chegar à resposta, o professor deverá pensar sobre sua relação com a obra. Lê-la não é o mesmo que a conhecer em seus detalhes, a fim de se estabelecer a forma mais adequada para se trabalhar em sala de aula; (c) com qual método devo trabalhar essa obra? pergunta que envolve os conhecimentos metodológicos, para que se afaste do que Cosson (2014, p. 106) denomina um "vale tudo [...] transformando-se em uma atividade de recreação." Ratificando a imprescindibilidade do aspecto teórico-metodológico, Aguiar e Bordini entendem que

[a]s teorias literárias [...] possibilitam variadas visões do objeto de ensino do professor - a literatura. Por meio delas a seleção dos textos pode ser realizada, segundo a ótica que melhor se adaptar às necessidades dos alunos e do projeto de educação pelo qual o professor opta. De igual modo, elas proporcionam procedimentos de trabalho com o texto literário coerentes com a concepção de literatura do professor e os princípios que norteiam sua atividade docente. (1993, p. 31). 
Além do conhecimento teórico, o professor deverá estar sensível quanto à condição de seus alunos, seja em relação à sua vida no interior da escola, seja fora dela. De que adianta o professor levar um texto considerado como cânone da literatura, se os alunos não estiverem preparados para sua leitura? E, mesmo os alunos preparados e o professor teoricamente embasado, qual o sentido de empregar metodologias inapropriadas para se trabalhar um texto com uma determinada turma? Essa sensibilidade de que falamos, dificilmente, é nata. Na maioria das vezes, o professor a adquire com a vivência em sala de aula, somada aos estudos teóricos e às leituras literárias. A troca de experiências e as reflexões sobre o seu fazer docente certamente o conduzirão para a aquisição desse saber, desde a formação inicial até o exercício profissional. Ademais, o professor deverá reunir conhecimentos cumulados ao longo da vida enquanto leitor de textos literários, ou seja, o professor deverá ser, de fato, leitor. Nesse sentido, Porto, Silva e Rettenmaier (2015, p. 30) classificam esse requisito como "[...] um traço fundamental que todo professor e não apenas daquele que trabalha especificamente na área de linguagens e código". Tratando do gosto pela leitura como característica imprescindível do professor, os autores vão além:

Não se pode ensinar aquilo que não se conhece. Se o professor ignora a leitura, o prazer e as potencialidades que ela traz, dificilmente terá condições de mostrar e convencer os seus alunos de que a leitura é uma ação necessária para a sua formação e um hábito a ser cultivado. (PORTO; SILVA; RETTENMAIER, 2015, p. 30).

Em se tratando de professores que formam leitores, como podemos perceber, esse gosto não pode ser latente, mas vivo, e advindo de uma prática contumaz. O professor de literatura deve ser um leitor acima de tudo, ter um vasto repertório, para poder fazer escolhas certas; deve ainda ser um conhecedor da teoria literária e pedagógica para, ao escolher adequadamente a obra para seus alunos, conseguir obter sucesso em seu papel como mediador.

Em relação à formação do leitor professor, pesquisa realizada por Duarte, Formiga e Inácio (2018) revela o reconhecimento dos futuros docentes sobre a importância do papel da leitura literária no decorrer de sua vida escolar e a necessidade de conhecimento de metodologias voltadas à formação de leitores. Os resultados ainda apontam para um discurso voltado às reflexões sobre as condições de sua formação no contexto das práticas de leitura e a consequente atuação docente.

Em pesquisas sobre o ensino e a formação de professores, Tardif (2002), com o objetivo de analisar o trabalho do professor em suas mais variadas interações, disserta sobre os quatros saberes implicados na atividade docente: saberes da formação profissional, saberes disciplinares, saberes curriculares e saberes experienciais. Destacamos aqueles referentes à formação dos professores, definidos como um agrupamento de saberes que, baseados nas ciências e na erudição, são disseminados durante o processo de formação inicial e/ou continuada.

Os saberes que servem de base para o ofício do professor também englobam os provenientes da experiência de "natureza social", mas também individual, entre outros saberes. Nesse sentido, o autor observou que professores hierarquizam os saberes constituídos durante a prática e, nessa ótica,

[...] os saberes oriundos da experiência de trabalho cotidiana parecem constituir o alicerce da prática e da competência profissionais, pois essa experiência é, para o professor, a condição para a aquisição e produção de seus próprios saberes profissionais. Ensinar é mobilizar 
uma ampla variedade de saberes, reutilizando-os no trabalho para adaptá-los e transformá-los pelo e para o trabalho. A experiência de trabalho, portanto, é apenas um espaço onde o professor aplica saberes, sendo ela mesma saber do trabalho sobre saberes, em suma: reflexividade, retomada, reprodução, reiteração daquilo que se sabe naquilo que se sabe fazer, a fim de produzir sua própria prática profissional. (TARDIF, 2002, p. 21, grifos do autor).

Assim, diante desse cenário nos perguntamos, afinal - já que estamos tratando da formação literária de profissionais da Pedagogia -, quais competências e saberes docentes são necessários para complementar a formação de um professor que tem pouca base teórica sobre o campo literário? E, especificamente, um professor que lida com a literatura infantil e juvenil? Inicialmente, podemos afirmar que são todos aqueles que fazem parte da formação pedagógica (didáticas, metodologias, avaliação etc.), completados pelos conhecimentos do campo literário, entre eles as teorias e a didática do ensino de literatura (suas metodologias, por exemplo).

Ainda no que se refere às competências específicas de literatura infantil e juvenil para dirigir situações de aprendizagens, temos que conhecer "[...] os conteúdos a serem ensinados e sua tradução em objetivos de aprendizagem [...]” (PERRENOUD, 2016, p. 69). Para tanto, os professores, durante a formação continuada, precisam mobilizar os saberes já conhecidos na formação inicial e os decorrentes sua prática docente. Importante notar que "[...] conhecer os conteúdos a serem ensinados é a menor das coisas quando se pretende instruir alguém. Contudo, a verdadeira competência pedagógica não está aí. Ela consiste, de um lado, em relacionar conteúdos a objetivos e, de outro, a situações de aprendizagem" (PERRENOUD, 2016, p. 69, grifos do autor).

Para Tardif (2002), um dos grandes problemas da docência tem sido a falta de sistematização individual e coletiva das experiências desses profissionais, pois os saberes docentes não se constituem apenas da vivência acumulada de anos de sala de aula, e, especialmente, quando demandam saberes específicos provenientes de campos particulares do conhecimento e da ciência; em nosso caso particular da literatura infantil e juvenil. Nesse sentido, as concepções de Tardif contribuem para as discussões sobre a formação do professor, para pensarmos quão é importante a mobilização de conhecimento dos professores, principalmente daqueles que lidam com a educação de crianças, etapa crucial no desenvolvimento da identidade socioafetiva e intelectual do ser humano.

\section{O livro de imagem e os elementos visuais}

Antes da abordagem metodológica e descritiva da formação que relatamos neste trabalho, entendemos como conveniente tratarmos ainda que brevemente, sobre aspectos formais do livro de imagens que utilizamos na formação continuada dos professores, para maior aproximação com a ferramenta da qual lançamos mão, bem como justificar a nossa escolha.

Há indícios de que, desde a pré-história, o homem usava as imagens para o registro de eventos cotidianos, para a narrativa de histórias e para se comunicar. Hodiernamente, o papel que essa forma de expressão desempenha na nossa sociedade não deixou de ter grande importância. Para onde quer que olhemos, notaremos uma imagem, por menor que seja e por mais imperceptível que nos pareça, mas, para além das experiências cotidianas, a imagem está na arte, inclusive na literatura por meio dos livros de imagem. Este, enquanto objeto de fruição estética, requer do docente um letramento diferenciado e necessário para a compreensão do funcionamento dos 
elementos pictóricos que fazem parte de uma obra literária, como condição de oferecer aos seus alunos uma leitura plena dessa expressão artística.

Apesar de haver dissenso quanto à nomenclatura, podemos distinguir o livro de imagem de outros suportes que possuem desenhos em seu interior, especialmente, do livro com ilustração, o que pode suscitar alguns conflitos quanto ao entendimento. $\mathrm{O}$ livro de imagem, para Linder (2011, p. 24), refere-se a "[o]bras que apresentam um texto acompanhado de ilustrações. O texto é espacialmente predominante e autônomo do ponto de vista do sentido. O leitor penetra na história por meio do texto, o qual sustenta a narrativa.”. Os livros ilustrados, conforme denomina Linder (2011) ou, como empregamos neste artigo, livros de imagens são "[o]bras em que a imagem é espacialmente preponderante em relação ao texto, que aliás pode estar ausente (é então chamado, no Brasil, de livro-imagem)." (2011, p. 24), é o caso da obra de Michelle Iacocca utilizada na formação continuada que relataremos mais adiante.

O texto de imagem, portanto, são "obras mudas", ou seja, não apresentam a linguagem escrita, mas nem por isso deixa de construir uma narrativa, o que faz utilizando-se somente de "imagens falantes". Tais obras apresentam-se como muito mais abertas que as demais, devendo, assim, ser consideradas imprescindíveis pelo docente, já que, nos dizeres de Castanha (2008, p. 148), "[s]em barreiras da língua, o entendimento da imagem torna-se universal, porque o idioma da imagem é a própria imagem."

Oliveira (2008, p. 29) esclarece que “[...] para ler uma imagem é impossível adotar um método rígido, um sistema, por exemplo, que avalie unicamente as questões estruturais - ritmo, linho, cor, textura etc.”. Na esteira desse pensamento, vários aspectos formais da obra devem ser observados, uma vez que contribuem para a construção da narrativa, pois as imagens irão, por exemplo, expressar os sentimentos dos personagens, transmitir a ideia de movimento, de modo a despertarem sensações, questionamentos e leituras variadas nos leitores. Para tanto, o artista emprega técnicas visuais próprias, a fim de que a linguagem seja eficaz e proporcione momentos de fruição estética. Nesse sentido, Oliveira (2008, p. 30) explica que "[t]oda ilustração, além de suas inter-relações com o texto [o que não se dá nos livros de imagens], possui qualidades configuracionais e estruturais perfeitamente explicáveis e analisáveis."

Como aspectos formais ou fundamentos da linguagem visual importantes para a compreensão da obra, Oliveira (2008) ainda elenca: a cor, o cenário, a perspectiva, o ritmo e a composição. A cor, para ele, é o elemento que apresenta "maior poder emotivo e evocativo." (OLIVEIRA, 2008, p. 50). Já o cenário se configura como um importante elemento para construção "[d]a atmosfera dramática através do ângulo em que cena está sendo vista. $\mathrm{O}$ ilustrador utiliza fundamentalmente diversos fatores, como a cor, a luz e, principalmente, a perspectiva, para construir o drama narrativo de suas ilustrações." (OLIVEIRA, 2008, p. 53-54). Ao passo que a perspectiva representa uma "[...] seleção do modo de ver a cena cria uma intimidade com o leitor, com o tipo de visão que ele está usufruindo [...].” (OLIVEIRA, 2008, p. 54).

A Fig. 1, a seguir apresentada, em consonância com o que elencamos, permitenos perceber o papel que o artista confere à personagem Bambolina e às ações que lhe são impingidas por seu dono: um protagonismo que irá vincular o leitor afetivamente à boneca desde o início da narrativa. Conforme podemos notar, na sequência das imagens da narrativa, não há nada mais além dos personagens. A ausência de um cenário cheio de detalhes, o uso de cores leves e em tons pastéis são recursos que convocam a atenção do leitor para a ação e para os personagens. 
Figura 1

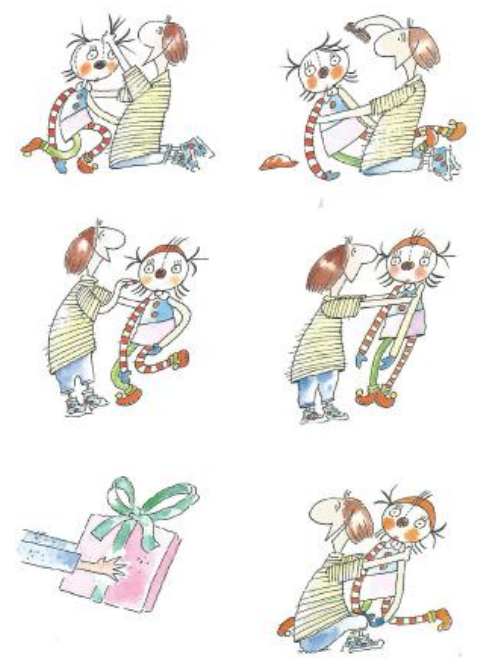

Fonte: Iacocca (2007, n.p.).

Oliveira (2008, p. 54) expõe que "[o] uso do espaço - que poderíamos chamar de cenográfico - pelo ilustrador aumenta o poder de persuasão da imagem." Assim, Iacocca sai da intimidade do lar do menino, onde ele e a boneca são o centro de interesse, para o "mundo lá fora". A fim de expressar esse mundo, o artista utiliza o cenário como forma de apresentar ao leitor as "aventuras" da protagonista, com o objetivo de diferenciar os ambientes pelos quais a boneca transita.

Na Fig. 2, por exemplo, o abandono fica evidente quando se dá a mudança de cenário. Nessa visão percebemos que a Bambolina é defenestrada do cenário interno, detalhado pela presença da janela (Fig. 1), caindo no exterior da casa, marcado pela sua fachada, onde aparece a mesma janela pela qual a boneca fora lançada, ao alcance do portão da rua e das árvores. Tal mudança de cenário, portanto, requer um uso maior do espaço, de maneira que, para manter a continuidade da narrativa, os detalhes do espaço ficcional se fazem necessários.

Figura 2

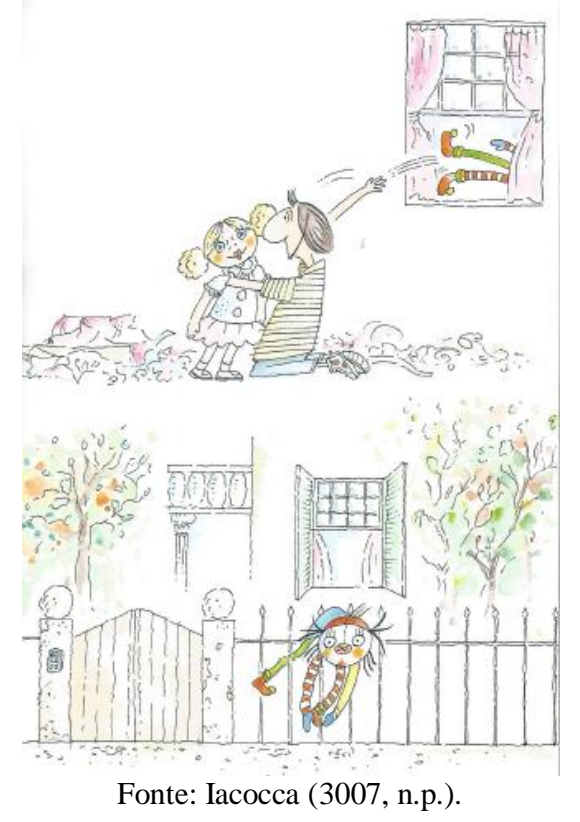


Acerca do ritmo, é considerado como "[a] justaposição de elementos antagônicos ao longo de todo livro." (OLIVEIRA, 2008, p. 58), não se limitando à disposição das ilustrações, contudo as alcança, isso porque "[a] compreensão de ritmo deve ser a mais abrangente possível. O ritmo possibilita o fluir das páginas, a sequencialidade espacial das ilustrações e sua relação física com um texto." (OLIVEIRA, 2008, p. 58). Em As aventuras de Bambolina, o ritmo acompanha a ação recebida pela personagem protagonista, a partir dos "abandonos" de seus proprietários, de modo que as ilustrações narram as ações dos personagens secundários sempre relacionadas à boneca e as consequências dessas ações sobre a boneca.

Quanto à perspectiva, a obra, na maioria das ilustrações, apresenta o ângulo médio, em que a cena é construída como se estivesse à altura dos olhos do leitor (Fig. 1 e 2), mas também apresenta, embora em número menor, os ângulos superior (Fig. 3) e inferior (Fig. e 4), em que a cena ocorre, respectivamente, abaixo e acima do olhar do leitor.

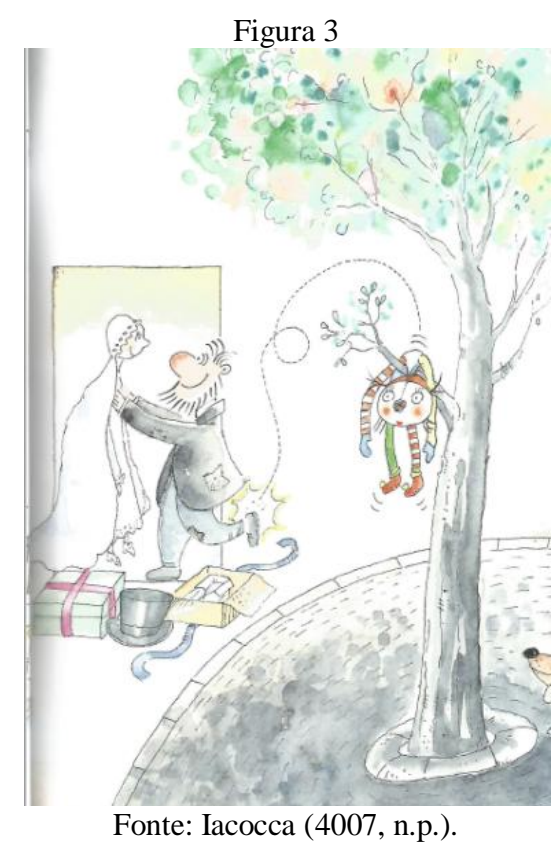

A composição, mais um elemento da narrativa por imagens, colabora fortemente para a leitura e a compreensão da obra, tendo em vista que "[...] ela organiza e une todos os elementos que participam de uma narrativa visual, relacionando-os de forma equilibrada com a área útil de ilustração, bem como com a página do livro" (OLIVEIRA, 2008, p. 60), favorecendo a leitura da narrativa. Na composição da obra de Iacocca, este artista compõe as imagens de forma diversificada no decorrer da narrativa, pois ora há imagens únicas que ocupam toda a página (Fig. 3, 4 e 5), ora em sequência como nas Fig. 1 e 2.

Note-se que a composição "[p]ermite elaborar uma página harmoniosa, onde se pode identificar a importância de cada um dos objetos ou personagens representados." (CASTANHA, 2008, p. 149). Isso é o que exatamente ocorre em As aventuras de Bambolina, em que as imagens destacam o que se pretende enfatizar na trajetória da boneca. 


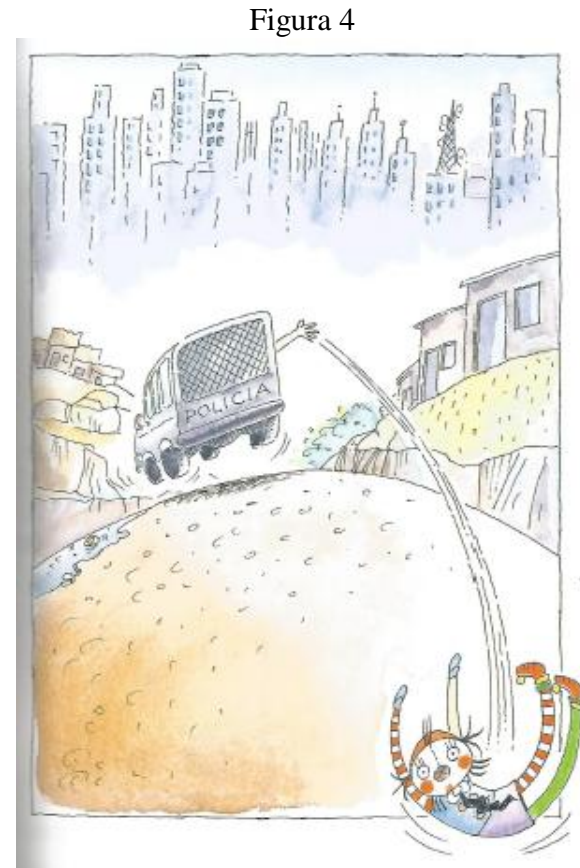

Fonte: Iacocca (5007, n.p.).

Quanto aos fundamentos da linguagem visual abordados, duas categorias também importantes para a leitura do livro de imagens são: o tempo e o espaço. Na obra de Iacocca, a sucessão de ações permite ao leitor a compreensão de que o tempo da narrativa se dá em poucos dias e de forma linear. Nas primeiras ilustrações do livro (Fig. 1), temos o menino brincando com a Bambolina até lançá-la pela janela ao receber um presente e, na última (Fig. 5), vemos a boneca ser aplaudida pelo público, após ser recuperada pelo seu último dono. Entre uma e outra cena, todas as ações da história são "contadas" compondo uma unidade narrativa: a relação do menino com a boneca Bambolina, o surgimento de uma nova boneca, o abandono da primeira, o encontro da boneca com diversos donos e seus sucessivos abandonos até o final feliz, sempre de forma linear.

Vários são os espaços ficcionais onde se desenvolve o enredo: a casa do menino, seu primeiro dono; a rua, quando o artista de rua a recolhe do muro e quando os meninos sem teto a levam consigo; a delegacia, ao ser apreendida; o lixão ao ser abandonada pela última vez etc. Em todos os espaços ficcionais por onde anda Bambolina, Iacocca traz elementos caracterizadores que permitem ao leitor a sua fácil identificação, mas sem grande esforço de detalhamento o que permite ao leitor embarcar no mundo imaginário suscitado pela obra, preenchendo as "lacunas" que as imagens suscitam. 


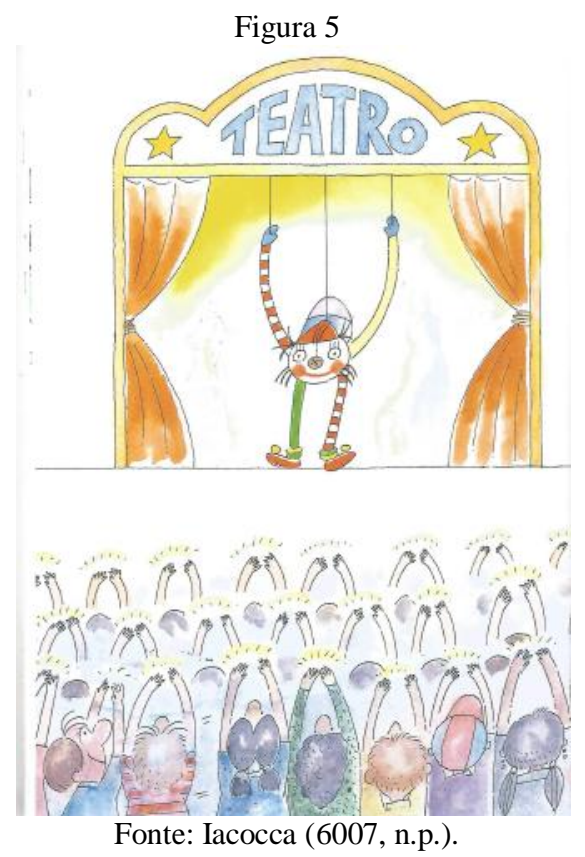

Além dos elementos apontados, não podemos deixar de notar o papel do leitor do livro de imagens. Acerca disso, Ramos (2013, p. 109) ressalta que "[n]em todo livro de imagens é construído a partir de um roteiro ou de uma história já conhecida. Quando se depara com um livro-imagem cuja narrativa é inédita, o leitor se torna responsável por criar o texto verbal. [...]". O artista, assim, fornece ao leitor elementos visuais da narrativa - imagens que compõem o livro, deixando para o leitor a responsabilidade pelo aproveitamento máximo do texto-imagem, o que significa criar um texto-verbal e não mera descrição das ilustrações. Esse aproveitamento dependerá, como apresenta Ramos (2013), do repertório de leitura, da capacidade imaginativa, dos conteúdos emocionais do leitor, bem como, acentuamos, da mediação do professor.

Impende esclarecer que o conteúdo teórico sobre os elementos do livro de imagens que tratamos nesta seção foram abordados indiretamente na formação dos professores, tendo em vista que as estratégias de leitura foram o objetivo central de discussão. Todavia, entendemos pela pertinência de trazermos esse conhecimento para este trabalho, uma vez que poderá colaborar para o letramento do profissional que o consultar.

\section{Metodologia}

Nesta seção, apresentamos a metodologia empregada durante a formação continuada que ora passamos a relatar. As etapas que configuram o nosso percurso metodológico foram as seguintes: i. Planejamento da formação; ii. Execução da formação (a. Contação; b. Exposição teórica, e c. Oficina de leitura).

Na primeira etapa, destinada ao planejamento da formação, o material teórico foi selecionado pela professora coordenadora, a fim de o grupo de orientandos que participam do processo de formação, voluntariamente, pudesse estudar e/ou revisar o conteúdo básico para a discussão a ser realizada no encontro com os professores. Então, previamente, a coordenadora disponibilizou esse material teórico para o grupo e também para os professores da escola - "Estratégias de leitura: para ensinar alunos a lerem e a compreenderem o que leem", capítulo 2 da obra Ler e compreender: estratégias de leitura, das autoras Cyntia Graziella Guizelin Simões Girotto e Renata Junqueira de Souza -, e o texto literário que foi trabalhado na oficina com os 
professores em formação continuada, As aventuras de Bambolina (2006), do escritor e ilustrador Michelle Iacocca. Além disso, foi estabelecido um plano de execução para a realização da formação com os professores.

Para a primeira parte da segunda etapa, a contação, organizamos a dinâmica de acordo com o gênero mesa redonda. Para esse momento, utilizamos Datashow, notebook, a obra literária mencionada, a boneca de pano Bambolina e adereços e roupas para a boneca. Notemos que sempre que possível iniciamos a formação com a contação da obra literária, para, então, partirmos para o estudo teórico.

$\mathrm{Na}$ contação, adotamos como metodologia os momentos "antes", "durante" e "depois" da leitura tratados por Solé (1998) e por Dalvi e Silva (2016). No momento "antes" da leitura, começamos o trabalho interativo com os professores já considerando a estratégia de leitura a ser trabalhada na formação, no caso a conexão; assim, realizamos questionamentos relacionados à temática da obra literária, a fim de conduzirmos os professores para o estabelecimento de conexão em relação a sua realidade e a sua experiência. Desse modo, tomando como base a atividade desenvolvida por Dalvi e Silva (2016), mostramos a boneca Bambolina, permitindo que os professores a manuseassem e, em seguida, levantamos os seguintes questionamentos:

- Vocês se lembram da sua primeira boneca?

- Como era essa sua boneca?

- Vocês ainda têm essa boneca?

- O que vocês fizeram com ela?

- Vocês já deixaram uma amizade por outra?

- O que vocês sentiriam se um(a) amigo(a) substituísse vocês por uma nova amizade?

Esse momento, de acordo com Solé (1998), é destinado à ativação dos conhecimentos prévios dos leitores, no caso os professores. Assim, os questionamentos suscitados, além de despertarem a curiosidade do leitor, visam à facilitação da compreensão da narrativa, mediante confirmação ou negação das inferências levantadas, bem como em razão das conexões que serão levantadas no decorrer da leitura da obra literária.

No momento seguinte, "durante" a leitura, realizamos a contação da narrativa, fazendo indagações relacionadas ao enredo da obra à medida que a história estava sendo contada, como, por exemplo, o sugerido por Dalvi e Silva (2016, p. 53) em sua sequência: "Que tipos de permutas acontecem?"

$\mathrm{Na}$ passagem da obra representada pela Fig. 2, realizamos questionamos aos professores, tais como: "O menino jogou a Bambolina pela janela. Por que ele fez isso?". A resposta indicada pelo enredo é o fato de o personagem ter ganhado uma boneca nova. Então ele substitui sua antiga boneca, a Bambolina, por outra. Essa constatação, muito possivelmente, levaria o leitor, seja ele os professores ou leitores crianças, a fazer conexão com aquilo que foi discutido no momento "antes" da leitura. Desse modo, procedemos durante toda a leitura da obra.

Ainda fundamentados em Solé (1998), constatamos que, além de nesse momento os leitores procederem com a confirmação, rejeição ou retificação das antecipações ou expectativas criadas no "antes" da leitura, e procederem com a identificação de referências a outros textos, eles também formularam hipóteses quanto ao desfecho da narrativa.

No caso da formação continuada que relatamos, o momento "depois" da leitura ficou reservado para após a exposição teórica, quando realizamos a oficina com os 
professores. Portanto, para efeitos didáticos desse trabalho, apresentamos, primeiramente, a metodologia da etapa de exposição teórica, para então tratarmos do referido momento de leitura.

Na etapa da exposição teórica, levamos para discussão os conteúdos constantes do texto de Girotto e Souza (2010). Durante essa etapa, foram apresentados, com o uso de recursos audiovisuais, conceitos-base pertinentes à compreensão de estratégias de leitura como o de metacognição, o de letramento ativo e mesmo o de estratégias de leitura. Tratamos das quatro condições para compreensão do que se lê: conhecimento prévio, identificação das características do texto que está sendo lido, contexto da leitura e estratégias de leitura. Abordamos as etapas da leitura, tal qual realizamos com os professores e explicamos a estratégia conexão, fazendo menção constantemente à contação realizada naquela formação, a qual serviu de ilustração para o que estava abordado teoricamente.

Por fim, no momento "depois" da leitura, foi lançada a proposta para os professores dramatizarem a narrativa e, ao final, cantarem a música "É tão lindo!", de autoria de Diogo Poças, gravada pela Turma do Balão Mágico, que aborda o tema amizade. Assim, distribuímos os personagens da obra entre os professores e organizamos a apresentação de acordo com as "aventuras" da Bambolina. Em seguida, os professores fizeram um ensaio geral, para, então, realizarem a apresentação definitiva.

\section{Resultado e discussão}

Conforme expomos na primeira seção desse artigo, uma formação docente adequada para o ensino da literatura requer a reunião de inúmeros saberes, entre eles o conhecimento teórico pedagógico e literário, além daqueles reunidos durante a experiência enquanto leitor de textos literários, bem como apreciador da leitura, pois

[m]unido de vínculo afetivo com a criação literária e de posse dos conhecimentos teóricos, o professor pode desenvolver uma série de procedimentos pedagógicos que ampliem as possibilidades de abordagem de leitura literária no âmbito escolar, de maneira a promover o acesso a esse gênero e ao conhecimento de muitos clássicos da literatura. (FORMIGA; INÁCIO; BARBOSA, 2015, p. 174).

Uma formação, portanto, ideal para o ensino da literatura compreende no que as estudiosas nos revelam, mas, se a formação inicial não dá conta de preencher todas essas questões, entra aí a formação continuada. Nessa perspectiva, notamos a importância de o professor ter acesso a cursos que objetivem além de ampliar, atualizar, preencher vazios deixados pela formação inicial.

Quem se dedica ao estudo do ensino de literatura e à formação literária do leitor iniciante, ou leitor jovem, muito tem se deparado com discussões sobre a crise de leitura e a indeterminação do lugar da literatura dentro do espaço literário. Deslocando-se, porém, da esfera da discussão acadêmica, podemos observar que muito há que se fazer na prática, daí a importância de sairmos do plano do debate para partirmos para a intervenção sobre a problemática.

Durante a formação que vem sendo realizada na escola, objeto desse relato de experiência, notamos que muitas lacunas vêm sendo preenchidas no tocante ao ensino da literatura, mais propriamente no que diz respeito à leitura literária. No caso da formação ora relatada, observamos que as estratégias de leitura eram desconhecidas 
pelos professores da escola e, o mais questionável, as obras literárias eram utilizadas como pretexto para o ensino de outros conteúdos.

Considerando que o público da referida instituição são crianças dos anos iniciais do Ensino Fundamental I, situados na etapa de alfabetização, em que a literatura pode ser trabalhada concomitantemente com o processo de decodificação, o conhecimento sobre estratégias de leitura é inegavelmente necessário para a promoção do letramento, da compreensão leitora e mesmo da formação enquanto leitor literário. Nessa perspectiva, o letramento não pode ser mais dissociado da etapa de alfabetização, visto que, de acordo com Magda Soares (2004, p. 15), há “[...] uma vivência intensa e diversificada, pela criança, dos usos e práticas sociais da língua escrita, o que significa interagir com materiais reais de leitura e escrita.".

Desse modo, o letramento literário, "[...] atende aos interesses da criança e possibilita uma alternativa de lazer e prazer, mas também por seu valor formativo a literatura infantil torna o mundo e a vida compreensíveis, porque revela outros mundos e outras vidas [...]" (SOARES, 2004, p. 15-16).

Nesse contexto, a abordagem teórica adotada durante a formação proporciona a construção de um saber que confere aos professores da escola uma base para a elaboração de planos de aula de leitura literária até antes não conhecida por eles. Ao ter contato com estratégias de leitura, como a conexão, podem conduzir as práticas de leitura de um modo mais eficiente para os fins almejados - alfabetização e letramento. Além de que, na formação, a maneira como o texto é contado pode servir de exemplo de como trabalhar a literatura em sala de aula, fazendo perceber que a leitura do texto literário requer planejamento e organização para que os objetivos da aula sejam alcançados, não havendo, portanto, espaço para o improviso destoante de procedimentos metodológicos adequadamente fundamentados.

A formação realizada, assim, vem para contribuir para o preenchimento de algumas lacunas, não se limitando tão somente às questões teóricas. No âmbito da prática de leitura, percebemos a construção de um prazer no que diz respeito à leitura literária. Os professores revelaram o encantamento pela narrativa e pela prática adotada naquela ocasião, o que, certamente, reverberará em sala de aula, visto que professores que apresentam comportamentos leitores têm mais chances de encantar seus alunos.

\section{Conclusão}

O trabalho com novos conceitos referentes à concepção do texto literário vem resultando em perceptíveis melhorias nas práticas de letramento literário dos envolvidos na formação inicial e continuada do docente, o que reflete em sua motivação e segurança frente ao texto literário para se trabalhar em sala de aula, bem como favorece o processo de mudanças do ensino/aprendizagem e, consequentemente, da formação leitora das crianças e dos professores.

Neste artigo, cujo objetivo é relatar a experiência vivenciada durante a formação continuada, apresentamos metodologias e procedimentos empregados para o estudo estratégico do texto, explorando, sobretudo, as conexões na contação da narrativa de imagens As aventuras de Bambolina (2006), de Michelle Iacocca; discutimos a respeito da formação dos professores e os saberes que precisam ser levados em conta para o trabalho exitoso com a literatura; e relatamos o desenvolvimento da prática de leitura realizada junto aos professores durante a formação.

Vale ressaltar que, na função de formadores de docentes, é gratificante acompanhar o processo de construção de novos saberes por parte dos professores envolvidos no projeto. No mais, esse processo também nos permite uma autorreflexão, 
ao passo que nos faz (re)pensar nossas práticas e reiterar a importância do planejamento para a leitura literária para o efeito do trabalho com o texto literário na Educação Infantil.

\section{Referências}

AGUIAR, Vera Teixeira de; BORDINI, Maria da Glória. Literatura: a formação do leitor, alternativas metodológicas. Porto Alegre: Mercado Aberto, 1993.

CASTANHA, Marilda. A linguagem visual no livro sem texto. In: OLIVEIRA, Ieda de. $O$ que é qualidade em ilustração no livro infantil e juvenil: com a palavra o ilustrador. São Paulo: DCL, 2008, p. 141-161.

COSSON, Rildo. Círculos de leitura e letramento literário. São Paulo: Editora Contexto, 2014.

DUARTE, Cristina Rothier; FORMIGA, Girlene Marques; INÁCIO, Francilda de Araújo. A quantas anda o leitor professor em formação? Trabalho apresentado no $56^{\circ}$ ICA - Congresso Internacional de Americanistas, 2018.

DALVI, Maria Amélia; SILVA, Adriana. A leitura em voz alta na educação infantil: o que ler e como ler. In: GIROTTO, Cyntia; SOUZA, Renata Junqueira (Org.). Literatura e educação infantil: para ler, contar e encantar. Campinas-SP: Mercado das Letras, 2016.

FORMIGA, Girlene Marques; INÁCIO, Francilda Araújo; BARBOSA, Socorro de Fátima Pacífico. Literatura, Escola e Formação literária: entre práticas e descaminhos. In: Revista Principia - Divulgação Científica e Tecnológica do IFPB, n. 28, p. 169-177, 2015.

LINDER, Sophie Van der. Para ler o livro ilustrado. São Paulo: Cosac Naify, 2011.

PERRENOUD, Philippe. Organizar e dirigir situações de aprendizagem. In: ZABALA, Antoni et al. Didática Geral. Trad. Carlos H. L. Lima et al. Porto Alegre: Penso, 2016.

PORTO, Ana Paula Teixeira; SILVA, Denise Almeida; RETTENMAIER, Miguel. Formação de leitores no Brasil: um processo de vários nós. In: Revista Língua \& Literatura, v. 17, n. 30, p. 28-37, 2015.

OLIVEIRA, Ruy de. Pelos Jardins Boboli: reflexões sobre a arte de ilustrar livros para crianças e jovens. Rio de Janeiro: Nova Fronteira, 2008.

RAMOS, Graça. A imagem nos livros infantis: caminhos para ler o texto visual. Belo Horizonte: Autêntica Editora, 2013.

SOARES, Magda. Alfabetização e letramento: caminhos e descaminhos. In: Revista Pátio, 2004, n. 29, p. 19-22.

SOUZA, Renata Junqueira de; GIROTTO, Cyntia Graziella Guizelim Simões. Estratégias de leitura: para ensinar alunos a lerem e a compreenderem o que leem. In: 
SOUZA, Renata Junqueira de et al. Ler e compreender: estratégias de leitura. São Paulo: Mercado de Letras, 2010, P. 45-114.

TARDIF, Maurice. Saberes docentes e formação profissional. Rio de Janeiro: Vozes, 2002.

Recebido em 20 de outubro de 2018

Aceito em 22 de novembro de 2018 